\title{
The effect of antifibrinolytic agents on the healing of modified Widman flaps in monkeys
}

\author{
A. Bergenholtz, R. G. Caffesse, C. E. Nasjleti, F. L. Bye and C. J. Kowalski \\ Department of Periodontology, University of Umea, School of Dentistry, Umea, Sweden; \\ Department of Periodontics and Dental Research Institute, The University of Michigan School of \\ Dentistry and Veterans Administration Medical Center, Ann Arbor, Michigan; and United States \\ Air Force Regional Hospital, Shaw Air Force Base, South Carolina, U.S.A.
}

(Accepted for publication October 20, 1983)

\section{Introduction}

In vitro studies have shown that addition of antifibrinolytic agents to culture media containing explants of cat palatal mucosa will change the direction of the epithelial proliferation. Consequently, the epithelial cells migrate in an opposite direction to that expected, reaching the stratum corneum and spreading in the upper surface with the formation of an everted epiboly (Bergenholtz, Gustafson \& Hänström 1977). This result suggests that it may be possible to change the pathway of migration of the marginal epithelium during wound healing after periodontal flap surgery or at least to postpone epithelial downgrowth until connective tissue cells of the periodontal ligament could repopulate the wound area (Nyman et al. 1982) and thus enhance connective tissue new attachment.

\section{Material and Methods}

Four adult Rhesus monkeys were used to evaluate the effect of antifibrinolytic agents in the healing of periodontal tissues following modified Widman flap procedures (Ramfjord \& Nissle 1974). The teeth were scaled and polished one week prior to sur- gery. No oral hygiene was provided during the experimental period. Modified Widman flaps were performed in all four quadrants under general anesthesia. Since no appreciable bone loss was present, alveolar crestal bone was removed in order to create a situation similar to that of periodontal disease. Notches were made in the roots at the level of the surgically established alveolar crest. The surgical procedure was modified in each quadrant in the following way: Quadrant 1: tranexamic acid crystals $(0.5 \mathrm{~g})$ were packed under the flap; Quadrant 2: 2 $\mathrm{ml}$ of epsilon aminocaproic acid (Amicar ${ }^{\circledR}$ [Lederle Laboratories Division of American Cyanamid Co., Pearl River, New York, USA], $250 \mathrm{mg} / \mathrm{ml}$ ) was locally injected; Quadrant 3: treatment 1 and 2 combined; Quadrant 4: control. The posterior area of the control flap was packed with $L$-leucine crystals (Sigma Chemical Co., St. Louis, Missouri, USA) while the anterior part did not receive any additional treatment. One monkey was treated in addition to the local treatment with daily injections of $5 \mathrm{ml}$ of aminocaproic acid for 7 days. The animals were sacrificed at 15,30 , and 90 days. Jouv specimens were processed for histological examination. For histometric analysis, forty longitudinal sections from each ex- 
perimental area depicting a visible notch were randomly selected. The histometric measurements included: (A) epithelial migration - distance from the gingival margin to the bottom of the junctional epithelium; (B) connective tissue attachment or adaptation - from the apical margin of the notch to the bottom of the junctional epithelium; and $(\mathrm{C})$ bone response - from the apical margin of the notch to the alveolar crest. This measurement was considered positive if bone was found coronally to the notch or negative if the alveolar crest was located apically to the notch.

\section{Results}

The results failed to show any marked difference among the various modalities tested. Clinically, all areas healed uneventfully.

Histologically, it was impossible to determine differences among the four regimens of treatment applied. The quality of healing obtained agrees completely with previous reports evaluating the healing of this type of flap surgery (Lahiffe, Caffesse \& Nasjleti 1978). All modalities of treatment demonstrated a marginal seal consisting of a long and thin junctional epithelium and areas of new connective tissue fibers attached to the root surface or running parallel to it.

Neither local injection nor placement of crystals in the surgical area gave any localized foreign body reaction in any specimen. When inflammation was seen within the tissues, it was associated with the accumulation of dental plaque. Therefore, antifibrinolytic agents appear to be well tolerated locally.

"Budding" of the marginal epithelium was observed at different time intervals and may indicate some tendency to change the direction of the migration of the epithelium immediately after healing. However, this was also observed in control quadrants, where the flap was raised and repositioned without placement of any agent in the wound. Therefore, "budding" may also be the result of a very close adaptation of the flaps to the teeth rather than an effect of the chemical treatment. Another possibility, which can not be excluded, is that the crystals of tranexamic acid and the injected aminocaproic acid may have had a systemic effect since the same histologic appearance was observed in the control and the experimental quadrants.

\section{Discussion}

The finding that there was no detectable effect of the antifibrinolytic agents on the epithelial growth direction in vivo, but that such change appears in vitro, is difficult to explain. One possibility could be the short exposure of the gingival epithelial cells to the antifibrinolytic agents. The biological half-life of tranexamic acid is about $2 \mathrm{~h}$, and $40 \%$ of a given dose will be excreted in the urine after $24 \mathrm{~h}$ (Andersson et al. 1968). Sixty to ninety percent of the aminocaproic acid will be recovered in the urine within 12 $\mathrm{h}$ after one single intravenous dose $(\mathrm{McNi}-$ col et al. 1962). Both agents are water

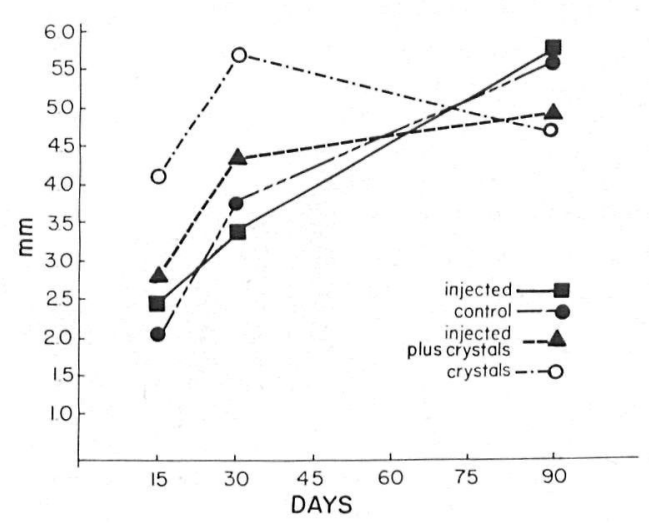

Fig. 1. Changes over time in the distance from the gingival margin to the bottom of the junctional epithelium. 


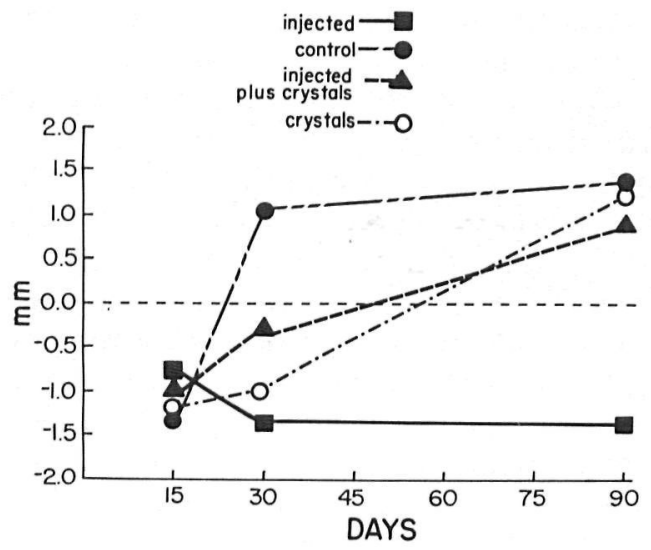

Fig. 2. Changes over time in the distance from the notch to the bottom of the junctional epithelium.

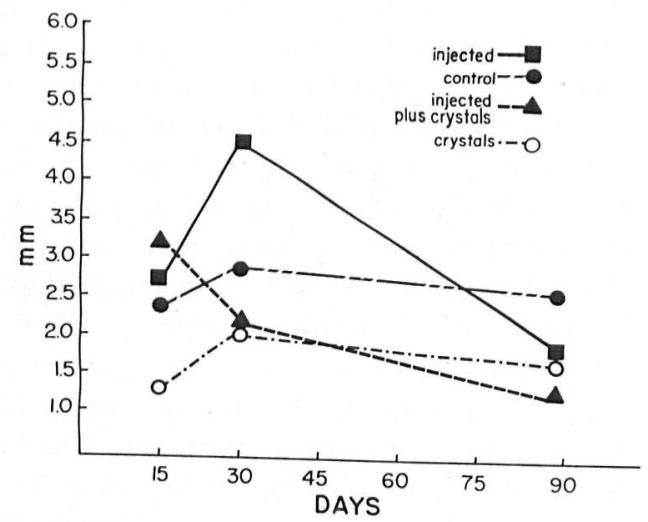

Fig. 3. Changes over time in the distance from the notch to the level of the alveolar crest. soluble, which means that the depot effect probably was rather short. Another possible explanation may be that local inflammatory cells present during the postsurgical healing have a fibrinolytic activity not inhibited by the antifibrinolytic agents used. Those may interact with fibrin and/or fibronectines on the epithelial cells, in spite of the presence of antifibrinolytic agents.

A possible further study would be to protect the surgerized areas with a dressing containing antifibrinolytic agents which could be slowly released to the wound. By doing so the in vivo environment would be more like the in vitro situation, where the epithelial cells are constantly exposed to the agents.

In the one-month specimens (local treatment only and local and systemic treatment) the epithelium had reestablished a junctional epithelium with varying extent of apical migration. In the three-month specimens a long junctional epithelium was established, which stopped at the level of new cementum; however, where cementum had not been formed, the epithelium reached the apical margin of the notch. New attachment and new bone formation were evident. There was minimal inflammation within the tissues. An interesting observation in sections from one particular tooth (a second

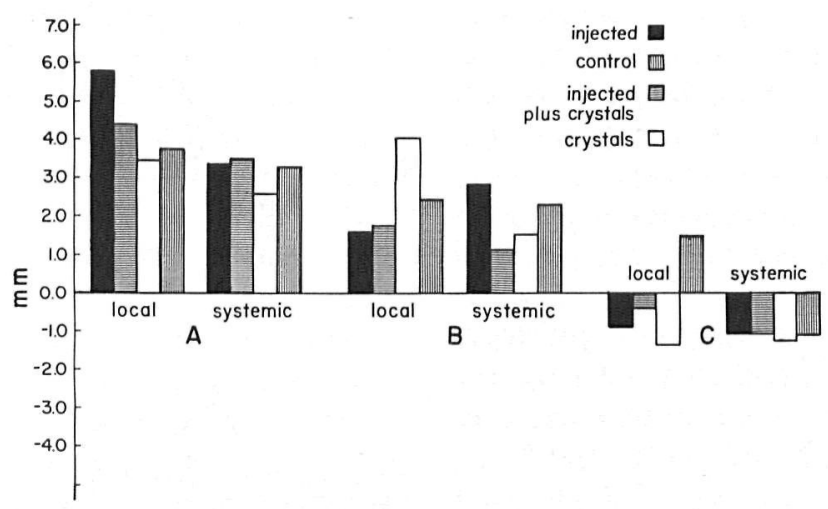

Fig. 4. Comparison of results with local and local plus systemic treatments at one month. 
premolar) in the area receiving aminocaproic and tranexamic acids was newly formed cementum overlapping the apical portion of the junctional epithelium.

Figs. 1 to 4 present a summary of the histometric measurements according to time interval and treatment. However, the small number of animals limits the use of statistics, and only trends can be indicated from these preliminary data.

Fig. 1 represents the changes with time of the distance A with the different local treatments applied and shows that the initial response was better when no drug was applied; at 90 days no difference was observed. Figs. 2 and 3 represent the changes over time for distances $\mathrm{B}$ and $\mathrm{C}$, respectively. Fig. 2 demonstrates an initially more favorable response concerning the connective tissue level when the area was locally treated with antifibrinolytic agents, but after 90 days there was no difference compared to the control specimens. In Fig. 3 , illustrating the bone response, all different areas initially elicited bone resorption, but at 90 days the response was better in the control.

Fig. 4 compares the results obtained after 1 month when local, and local plus systemic treatments were instituted. It is evident that none of the parameters evaluated benefited by the systemic addition of the drug. More bone was lost when the animal was treated systemically. Thus, the general trend seems to confirm that the less the surgical area is disturbed the better the healing result will be.

Within the limits of this study, it can be concluded that:

1. Antifibrinolytic agents, either locally or systemically applied, do not seem to improve the healing results obtained after performing flaps for new attachment and readaptation.
2. There seems to be no indication for the use of antifibrinolytic agents to improve the possibilities of new attachment after flap surgery.

\section{Acknowledgement}

This study was partially supported by the Medical Research Division of the Veterans Administration.

\section{References}

Andersson, L., Nilsson, I. M., Colleen, S., Granstrand, B. \& Melander, B. 1968. Role of urokinase and tissue activator in sustaining bleeding and management thereof with EACA and AMCA. Annals of the New York Academy of Sciences 146: 642.

Bergenholtz, A., Gustafson, G. T. \& Hänström, L. 1977. The effect of antifibrinolytic agents on wound healing in vitro. Experientia 33: 254.

Lahiffe, B. J., Caffesse, R. G. \& Nasjleti, C. E. 1978. Healing of periodontal flaps following use of MBR 4197 (Flucrylate) in Rhesus monkeys. A clinical and histological evaluation. Journal of Periodontology 49: 635.

McNicol, G. P., Fletcher, A. P., Alkjersig, N. \& Sherry, S. 1962. The absorption, distribution and excertion of epsilon aminocaproic acid (EACA) following its oral or intravenous administration to man. Journal of Laboratory and Clinical Medicine 59: 15.

Nyman, S., Gottlow, J., Karring, T. \& Lindhe, J. 1982. The regeneration potential of the periodontal ligament. An experimental study in the monkey. Journal of Clinical Periodontology 9: 257.

Ramfjord, S. P. \& Nissle, R. R. 1974. The modified Widman flap. Journal of Periodontology 45: 601 .

Address:

Department of Periodontology

University of Umea

School of Dentistry

Umea, Sweden 
This document is a scanned copy of a printed document. No warranty is given about the accuracy of the copy. Users should refer to the original published version of the material. 